\title{
Penile Chill Blains: a Case Report
}

\author{
Tanmay Pande $^{1}$ (D) $\cdot$ Amit Agrawal $^{2} \cdot$ Priya Ranjan $^{3}$
}

Received: 15 February 2021 / Accepted: 17 May 2021 / Published online: 22 May 2021

(C) Association of Surgeons of India 2021

\begin{abstract}
Chill blains or perniosis occurs in exposed body parts in extreme cold climate. It usually affects the tip of the upper limb, lower limb, tip of the nose or the ear lobules. It rarely occurs in the covered body parts. Chill blain usually affects the females. There are reports of occurrence of chill blains in unusual area which are covered. This case report is of a young male presenting as chill blain over the penile region. A 27-year-old male patient reported of pain and swelling of penile shaft following exposure to extreme cold climate in the month of September at high altitude. There was no history of trauma, ulcer over the penis, no blister, no discharge, or fever, with no history of cold related injuries in past. The examination revealed erythematous penile shaft with subcutaneous edema. There was no inguinal lymphadenopathy and the scrotal skin was normal. The patient responded to the conservative management for chill blains. Idiopathic penile chill blain is an extremely rare condition. People living in cold mountainous region should frequently change the clothes to keep the local area dry to avoid being victim of such cold related injuries.
\end{abstract}

Keywords Penile swelling $\cdot$ Idiopathic chill blain penis $\cdot$ High altitude $\cdot$ Extreme cold

\section{Introduction}

Chill blain also known perniosis occurs on exposure of body parts to extreme cold climate. It usually affects the digits of upper and lower limbs, tips of the nose and ear lobes, or the exposed body parts [1]. It is very unusual to find chill blains on a part which is always covered. We present such an extremely rare case in a young patient with chill blains of the penis.

\section{Case Presentation}

A 27-year-old local resident presented to a hospital in high altitude with complaints of burning pain and swelling of the penis for 5 days. He gave history of exposure to extreme cold climate, ambient temperature being -7 to $13{ }^{\circ} \mathrm{C}$ at an altitude of about 17,000 feet above mean sea level, where he had been for over a period of 2 months. He denied history of trauma,

Tanmay Pande

drtanmaypande88@gmail.com

Field Hospital, Ladakh, India

Command Hospital (Western Command), Panchkula, India

3 Command Hospital (Northern Command), Udhampur, India insect bite, vigorous masturbation, or sexual intercourse. There had been no history of swelling in the joints and skin lesions over other body parts, and the family history for such illness was negative. On local examination, the entire penis was erythematous with subcutaneous edema. There was no local rise of temperature, no blistering of the penile skin, no lesion on glans with retractable prepuce, and a normal urethral meatus. The scrotal skin was normal, and there was no inguinal lymphadenopathy. The examination of the hands and feet were normal. On investigation, his $\mathrm{Hb}$ is $19.3 \mathrm{~g} / \mathrm{dl}$, TLC $10,700 / \mathrm{mm}^{3}$, DLC P 78L16M02E04, platelets $161 \times 10^{\wedge} 3$, INR 1.1, urea $28 \mathrm{mg} / \mathrm{dl}$, S.Creat $1.1 \mathrm{mg} / \mathrm{dl}$, SGOT/SGPT 46/ $52 \mathrm{IU} / \mathrm{L}$, viral markers negative, urine RE/ME NAD and VDRL negative, and rapid antigen test (COVID-19) negative. He was managed with local hot fomentation and application of glycerine and lignocaine jelly. He was started on tab ecosprin $75 \mathrm{mg}$ and tab nifedipine $20 \mathrm{mg}$. His symptoms resolved completely in few days. On follow-up of the patient for 6 months, he had no recurrence.

\section{Discussion}

Chill blains are painful inflammatory lesions of the skin in response to exposure to extreme cold environment affecting the hands and feet [2]. The exact pathogenesis is unclear; 
however, the cold weather primarily induces vasospasms of the subcutaneous vessels, especially in the acral areas, thereby leading to injury of the epidermis and dermis [1].The duration of cold induced vasospasms is longer in symptomatic individuals than the asymptomatic ones [3]. The "Hunting's reflex" is deranged in such patients which is intermittent vasodilatation of these vessels to prevent permanent damage to skin by providing warm blood, intermittently, to areas exposed to cold [1].

Chill blains are primary or secondary to an underlying connective tissue disorder [4]. The primary or idiopathic chill blains occur on exposure to cold and damp weather manifesting as tingling or burning sensation of the affected part, swelling, itching, and development of blisters with clear or hemorrhagic fluid [2]. It commonly affects the digits, tip of the nose, and ears. The secondary chill blains are associated with connective tissue disorders like SLE, Behcets disease, and antiphospholipid syndrome [5]. The presentation is similar to primary chill blains; however, symptoms and lesions may persist beyond the cold weather [5]. The diagnosis is clinical with history of exposure to cold to affected part.

The management of the primary or the idiopathic chill blains consists of minimizing the exposure to cold and moist environment. Beyond this, many strategies and treatment modalities have been tried but not validated. The commonly employed management protocols include foot or hand parade with maintenance of the local hygiene by putting the affected part in lukewarm water [2]. This is accompanied by reducing the cold exposure by using double layer of woollen clothing. The drugs commonly used are calcium channel blockers, nifedipine, and antiplatelets, ecosprin. Pentoxifylline has also been used but not found to be effective [6]. In our patient, we had used nifedipine and ecosprin to which he responded well. Various kinds of topical ointments have also been used, but none of them are found to be of benefit (Figs. 1, 2 and 3).

Chill blains usually affect the acral areas (the palms and the soles, the volar surfaces of the fingers and toes, and the ungual areas), the tip of the nose, and the external ears. Anecdotal case reports have reported affection of unusual areas like the thigh and the buttocks $[7,8]$. To the best of the knowledge of the authors, this is the first time an isolated penile chill blain is being reported. Our patient had presented with erythema and edema of the penile shaft after exposure to cold although the penis was well protected by clothing. One of the possible reasons may be the damp microenvironment after a bout of perspiration in the area, and subsequent exposure to the cold, the temperature in the area would have dropped suddenly leading to the development of chill blains [2]. The diagnosis of chill blains is clinical, with no confirmatory test to affirm the diagnosis. The supplementary proof comes from the fact that the erythema and edema settled with treatment in lines of treating chill blains. Chill blains have been reported to be recurring in cold season; however, on follow-up of the said

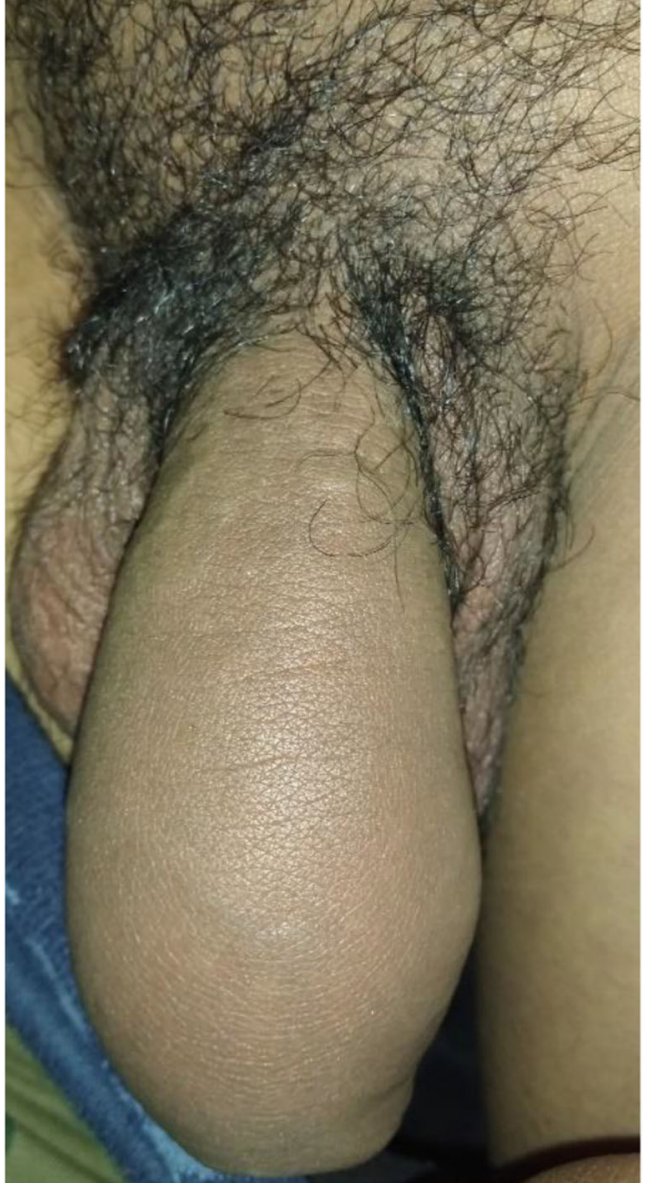

Fig. 1 Swelling seen on the day of presentation (erythema not well appreciated in the picture)

case, there has been no recurrence till date, possibly due to extreme rare manifestation of chill blains. There was no evidence of erectile dysfunction associated along with this rare manifestation.

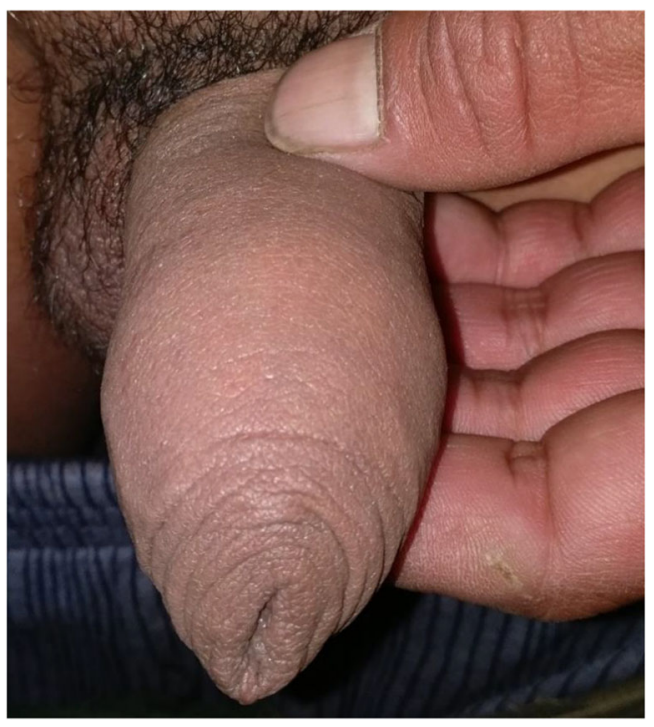

Fig. 2 Day 5 of the Treatment with reduction in swelling 


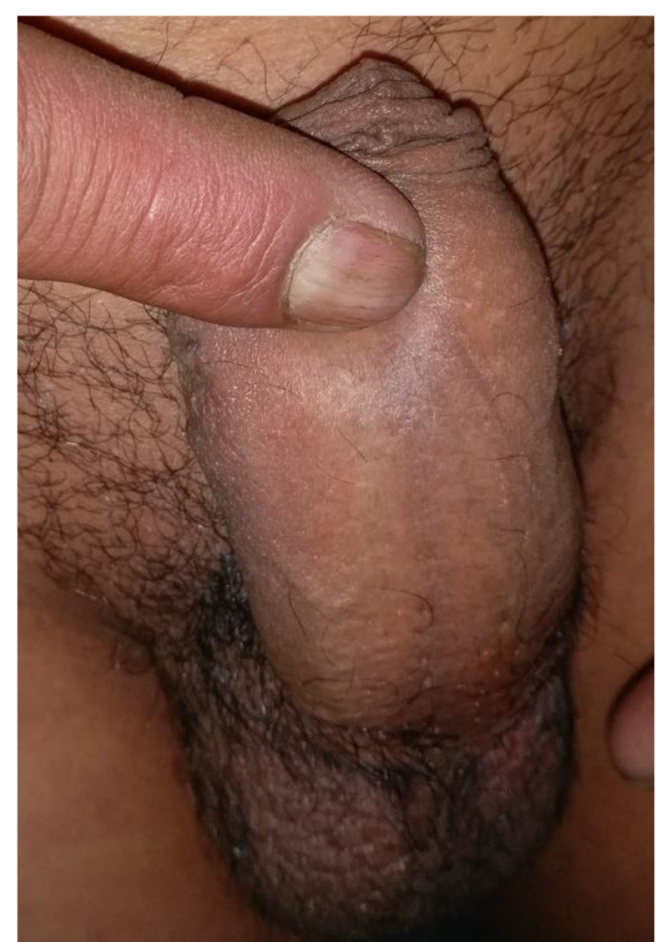

Fig. 3 At the time of discharge after 8 days

\section{Conclusion}

Isolated chill blain of the penis is an extremely rare condition never reported. People inhabiting such terrains need to maintain a dry and warm local environment by regular change of clothing, apart from routine precautions to avoid being victim of cold injuries.

\section{Declarations}

Conflict of Interest The authors declare no competing interests.

\section{References}

1. Prakash S, Weisman MH (2009) Idiopathic chilblains. Am J Med 122(12):1152-1155. https://doi.org/10.1016/j.amjmed.2009.07.011

2. Singh GK, Datta A, Grewal RS, Suresh MS, Vaishampayan SS (2015) Pattern of chilblains in a high altitude region of Ladakh, India. Med J Armed Forces India 71(3):265-269 Available from: https://linkinghub.elsevier.com/retrieve/pii/S0377123713000154. Accessed Jul 2015

3. Daanen HAM, Van Ruiten HJA (2000) Cold-induced peripheral vasodilation at high altitudes - a field study. High Alt Med Biol 1(4):323-329 Available from: http://www.liebertpub.com/doi/10. 1089/15270290050502390

4. Gordon R, Arikian AM, Pakula AS (2014) Chilblains in Southern California: two case reports and a review of the literature. J Med Case Rep 8(1):381 Available from: http://jmedicalcasereports. biomedcentral.com/articles/10.1186/1752-1947-8-381

5. Takci Z, Vahaboglu G, Eksioglu H (2012) Epidemiological patterns of perniosis, and its association with systemic disorder. Clin Exp Dermatol 37(8):844-849 Available from: http://doi.wiley.com/10. 1111/j.1365-2230.2012.04435.x

6. Nyssen A, Benhadou F, Magnée M, André J, Koopmansch C, Wautrecht J-C (2020) Chilblains. Vasa 49(2):133-140 Availablefrom: https://econtent.hogrefe.com/doi/10.1024/03011526/a000838. Accessed Mar 2020

7. Goette DK (1990) Chilblains (perniosis). J Am Acad Dermatol 23(2):257-262 Available from: https://linkinghub.elsevier.com/ retrieve/pii/019096229070209Z. Accessed Aug 1990

8. Price RD, Murdoch DR (2001) Case report: perniosis (chilblains) of the thigh: report of five cases, including four following river crossings. High Alt Med Biol 2(4):535-538 Available from: http://www. liebertpub.com/doi/10.1089/152702901753397108

Publisher's Note Springer Nature remains neutral with regard to jurisdictional claims in published maps and institutional affiliations. 